OPEN ACCESS

Edited by:

Anindya Chanda,

University of South Carolina,

United States

Reviewed by:

Lorant Hatvani,

University of Szeged, Hungary

Claudio Altomare,

Italian National Research Council, Italy

${ }^{*}$ Correspondence:

Xiujun Wen

wenxiujun@scau.edu.cn

Cai Wang

wangcai@scau.edu.cn

Specialty section:

This article was submitted to Fungi and Their Interactions,

a section of the journal

Frontiers in Microbiology

Received: 27 November 2019

Accepted: 23 March 2020

Published: 09 April 2020

Citation:

Wen $\mathrm{C}$, Xiong $\mathrm{H}$, Wen J, Wen X and Wang $C$ (2020) Trichoderma

Species Attract Coptotermes formosanus and Antagonize Termite

Pathogen Metarhizium anisopliae.

Front. Microbiol. 11:653.

doi: 10.3389/fmicb.2020.00653

\section{Trichoderma Species Attract Coptotermes formosanus and Antagonize Termite Pathogen Metarhizium anisopliae}

\author{
Chao Wen ${ }^{1,2}$, Hongpeng Xiong ${ }^{1}$, Junbao Wen ${ }^{3}$, Xiujun Wen ${ }^{1 *}$ and Cai Wang ${ }^{1 *}$ \\ ${ }^{1}$ Guangdong Key Laboratory for Innovation Development and Utilization of Forest Plant Germplasm, College of Forestry \\ and Landscape Architecture, South China Agricultural University, Guangzhou, China, ${ }^{2}$ Integrative Microbiology Research \\ Centre, South China Agricultural University, Guangzhou, China, ${ }^{3}$ Beijing Key Laboratory for Forest Pest Control, College \\ of Forestry, Beijing Forestry University, Beijing, China
}

Although subterranean termites live within soil, little attention has been paid on the potential interaction among subterranean termites and soil microbes. Herein, we conducted different choice tests to investigate aggregation and tunneling behaviors of Coptotermes formosanus Shiraki responding to soil/sand treated with conidia of seven soil fungi, Trichoderma longibrachiatum Rifai, Trichoderma koningii Oud., Trichoderma hamatum (Bon.) Bain., Trichoderma atroviride Karsten, Trichoderma spirale Indira and Kamala, Trichoderma harzianum Rifai, and Trichoderma viride Pers. ex Fries. In aggregation-choice test, soil treated with nearly all Trichoderma species tested (except T. koningii) significantly increased termite aggregation compared with untreated soil. In tunneling-choice tests, termites produced significantly larger tunnels in sand treated with T. longibrachiatum or T. koningii than that in untreated sand. We hypothesized that Trichoderma species could benefit termites by protecting them from infection of the entomopathogenic fungus Metarhizium anisopliae (Metschn) Sorokin, and three Trichoderma species that attracted termites (T. Iongibrachiatum, T. atroviride, and T. harzianum) were tested. The antagonism tests showed that the three Trichoderma species suppressed growth of $M$. anisopliae. Also, the median lethal time ( $\left.L T_{50}\right)$ of termites exposed to both Trichoderma species and $M$. anisopliae was significantly longer than termites exposed to $M$. anisopliae alone. Interestingly, though significantly fewer termites aggregated in soil treated with $M$. anisopliae conidia compared with untreated soil, $M$. anisopliae conidia mixed with T. longibrachiatum or T. harzianum were no longer repellent to termites. Our results showed that the fungi in the genus Trichoderma (1) exerted generally attractive effects on termites, (2) protected termites from the infection of entomopathogenic fungus, and (3) altered pathogen-avoiding behaviors of termites. Future studies will be required to understand the mechanisms underlying these newly discovered effects.

Keywords: Trichoderma, Coptotermes formosanus, attractiveness, entomopathogen, antagonism 


\section{INTRODUCTION}

Subterranean termites usually live in moist habitats that favor the growth of diverse microbes (Cornelius et al., 2012). The interaction among termites and some environmental fungi has been extensively investigated over the past few decades. For example, it is well known that the foraging activities of subterranean termites can be enhanced by the wood-rotting fungi and blue-staining fungi living in their food sources (Amburgey, 1979; Ohmura et al., 1995; Cornelius et al., 2002, 2004; Little et al., 2012a,b, 2013; Clay et al., 2017). Also, termites have evolved multiple strategies to escape entomopathogenic fungi and reduce epidemics within their colonies (Myles, 2002; Shimizu, 2003; Yanagawa et al., 2005; Yanagawa and Shimizu, 2007; Peterson and Scharf, 2016; Davis et al., 2018). Surprisingly, though subterranean termites excavate large amounts of soil and construct extensive tunneling systems underground, the potential interactions between subterranean termites and soil fungi have received little attention.

Trichoderma spp. are typical soil fungi that decompose dead wood, litters, or organic matters (Harman et al., 2004; Govarthanan et al., 2018). A few studies reported the commensalism between Trichoderma species and subterranean termites. For example, Zoberi and Grace (1990) isolated Trichoderma koningii Oud., Trichoderma harzianum Rifai, and Trichoderma viride Pers. ex Fries from the wood infested with Reticulitermes flavipes (Kollar). Jayasimha and Henderson (2007) isolated T. harzianum, Trichoderma virens (Miller, Giddens, and Foster) Arx, Trichoderma asperellum Samuels, Lieckf. and Nirenberg, and Trichoderma ghanense Doi, Abe, and Sugiyama from the integuments and guts of Coptotermes formosanus (Shiraki). Both studies identified Trichoderma species using conventional culture-based methods, and more Trichoderma species (especially for those that grow slowly or cannot grow well on the artificial media) might be detected in future studies using non-culture-based methods.

Interestingly, some recent studies showed that the interactions between subterranean termites and Trichoderma species are more complex than previously thought. For example, Xiong et al. (2018) reported that C. formosanus preferred to make tunnels in the soil previously treated with the commercial conidial formulations of T. harzianum (BioWorks ${ }^{\circledR}$ ) or T. viride (Shuiguxin ${ }^{\circledR}$ ) compared with the untreated soil. However, in that study only two commercially available Trichoderma species were tested, and it is unclear whether fungi in the genus Trichoderma generally attract C. formosanus. In this study, we conducted different choice tests to investigate the aggregation and tunneling preferences of C. formosanus responding to the soil treated with the unformulated conidia of seven Trichoderma species (Trichoderma longibrachiatum Rifai, T. koningii Oud., Trichoderma hamatum (Bon.) Bain., Trichoderma atroviride Karsten, Trichoderma spirale Indira and Kamala, T. harzianum Rifai, and T. viride Pers. ex Fries) and untreated soil. Among them, T. koningii, T. harzianum, and $T$. viride were previously isolated from live termites and their habitats (Zoberi and Grace, 1990; Jayasimha and Henderson, 2007). The remaining Trichoderma species are common in soils, and therefore may also affect behaviors of subterranean termites.

Since our studies showed a strong attractive effect of Trichoderma species to C. formosanus (see section "Results"), it would be valuable to study the biological significance of Trichoderma species on termites. Interestingly, Trichoderma species are well-known as plant symbionts that can inhibit the growth of many phytopathogenic fungi including Verticillium dahliae (Kleb), Pratylenchus brachyurus (Godfrey), and Fusarium graminearum (Schwabe) (Carrero-Carrón et al., 2016; Kath et al., 2017; Saravanakumar et al., 2018). Metarhizium anisopliae (Metschn) Sorokin is a common entomopathogenic fungus that lives in soils and attacks subterranean termites (e.g., Kramm et al., 1982; Zoberi, 1995; Jones et al., 1996; Wang and Powell, 2004; Wright et al., 2005; Denier and Bulmer, 2015). We hypothesized that Trichoderma species could suppress entomopathogenic fungi such as $M$. anisopliae and therefore benefit termites. In the present study, the antagonism tests were conducted to investigate whether Trichoderma species inhibit the growth of $M$. anisopliae under in vitro conditions. We also conducted the mortality tests to study whether Trichoderma species protect termites from the infection of $M$. anisopliae under in vivo conditions.

Many previous studies showed that entomopathogenic fungi such as M. anisopliae repelled termites (Hussain et al., 2010). All of these studies only tested the effect of $M$. anisopliae, but there are many types of soil microbes coexisting within soil under natural conditions. We hypothesize that the coexistence of Trichoderma species may disturb the pathogen-avoidance behaviors of termites triggered by M. anisopliae. Here, we conducted choice and non-choice tests to compare the aggregation and tunneling behaviors of termites reacting to the soil containing conidia of M. anisopliae alone, or containing conidia of both M. anisopliae and Trichoderma species.

\section{MATERIALS AND METHODS}

\section{Termites}

Four C. formosanus colonies were collected from campus and arboretum of South China Agricultural University (SCAU), Guangzhou, China, using the methods described by Xiong et al. (2018). The collection sites of the four termite colonies were $>500 \mathrm{~m}$ from each other. Termites collected from the same colony were transported to the moisture-proof storage container $(55 \times 40 \times 31 \mathrm{~cm}[\mathrm{~L}$ by W by $\mathrm{H}])$ with wet wood sticks, and maintained at room temperature $\left(24 \pm 2^{\circ} \mathrm{C}\right)$ under darkness for $<1$ month.

\section{Trichoderma Species and Metarhizium anisopliae}

Seven Trichoderma species ( $T$. longibrachiatum, T. koningii, $T$. harzianum, T. hamatum, T. atroviride, T. viride, and T. spirale) and one entomopathogenic fungus (M. anisopliae) were used in this study. T. longibrachiatum, T. atroviride, T. hamatum, T. spirale, and M. anisopliae were purchased from BIOBW Biotechnology Co., Ltd. (Beijing, China), and T. harzianum, T. koningii, and T. viride were purchased 
from Guangdong Culture Collection Center (GCCC) (Table 1). Based on the information provided by BIOBW and GCCC, these fungi were identified to the species level using the molecular methods. In brief, a specific fragment of the internal transcribed spacer (ITS) region was amplified using the primers ITS1 (5'-TCCGTAGGTGAACCTGCGG-3') and ITS4 (5'-TCCTCCGCTTATTGATATGC-3') (White et al., 1990), and the amplified DNA was sequenced and aligned against sequences of the type strain from the databank $\left(\mathrm{NCBI}^{1}\right)$. All fungi were cultured using potato dextrose agar (PDA) medium in an incubator at $25 \pm 1^{\circ} \mathrm{C}$. To obtain large amounts of conidia, sterile distilled water $(7 \mathrm{~mL})$ was added to the PDA cultures, and the conidial suspension was transferred to a $250 \mathrm{~mL}$ Erlenmeyer flask containing autoclaved rice $(50 \mathrm{~g}$ rice mixed with $50 \mathrm{~mL}$ distilled water, and sterilized at $121^{\circ} \mathrm{C}$ for $20 \mathrm{~min}$ ). The Erlenmeyer flask was maintained in an incubator at $25 \pm 1^{\circ} \mathrm{C}$ for 5-10 days until the rice medium was covered by large amounts of conidia. Sterile distilled water $(200 \mathrm{~mL})$ was added to the Erlenmeyer flask and shook for 3 min using a vortex mixer. The concentration of conidial suspension was determined using a hemocytometer (Shanghai Qijing Biochemical Reagent Instrument Co., Ltd, China). Sterile distilled water was added and mixed with suspensions to obtain required concentrations of conidia to set the bioassays.

\section{Soil/Sand Preparation}

Topsoil was collected from the two locations of arboretum of SCAU where C. formosanus activities have been detected. Samples of soil were sent to the Laboratory of Forestry and Soil Ecology (College of Forestry and Landscape Architecture, SCAU), and identified as sandy clay loam (70\% sand, $9 \%$ silt, and $21 \%$ clay) and loamy sand soil ( $78 \%$ sand, $14 \%$ silt, and $8 \%$ clay). Fine sand (Suqian Weiyou Trading Co., Ltd., China) was purchased. Soil and sand were sterilized at $80^{\circ} \mathrm{C}$ for 3 days, and completely

${ }^{1}$ http://www.ncbi.nlm.nih.gov/BLAST/

TABLE 1 | Information on fungi used in the present study.

\begin{tabular}{|c|c|c|c|}
\hline Fungal species & Strain No. & Source & $\begin{array}{l}\text { Source of } \\
\text { isolation }^{\text {d }}\end{array}$ \\
\hline Trichoderma Iongibrachiatum & Bio-68049a & $\mathrm{BIOBW}^{\mathrm{b}}$ & $\begin{array}{l}\text { Soybean (Glycine } \\
\max \text { L.) }\end{array}$ \\
\hline Trichoderma koningii & GIM-3.518 & $\mathrm{GCCC}^{\mathrm{C}}$ & Humus soil \\
\hline Trichoderma harzianum & GIM-3.442 & GCCC & Humus soil \\
\hline Trichoderma hamatum & Bio-08848 & BIOBW & $\begin{array}{l}\text { Broad bean (Vicia } \\
\text { faba L.) soil }\end{array}$ \\
\hline Trichoderma atroviride & Bio-08876 & BIOBW & $\begin{array}{l}\text { Panax notoginseng } \\
\text { (Burkill) rhizosphere }\end{array}$ \\
\hline Trichoderma viride & GIM-3.432 & GCCC & Humus soil \\
\hline Trichoderma spirale & Bio-088439 & BIOBW & Humus soil \\
\hline Metarhizium anisopliae & Bio-67986 & BIOBW & Soil \\
\hline
\end{tabular}

aTrichoderma longibrachiatum strain Bio-68049 is also referred to as Trichoderma longibrachiatum strain NBRC 31918, with the ITS sequence available at http://www.nbrc.nite.go.jp/NBRC2/NBRCDispSearchServlet. ${ }^{b} \mathrm{BIOBW}=\mathrm{BIOBW}$ Biotechnology Co., Ltd. (Beijing, China). ${ }^{C}$ GCCC = Guangdong Culture Collection Center. dinformation was obtained from BIOBW and GCCC. dried at $50^{\circ} \mathrm{C}$ for $>2$ weeks. To remove coarse particles, soil was sifted through a 2 -mm sieve, and sand was sifted through a 0.85 $\mathrm{mm}$ sieve. Required amount of conidial suspensions and sterile distilled water were added to prepare the wet soil (24\% (w/w) moisture, calculated using the formula as follows: [(wet weight - dry weight)/dry weight] $\times 100 \%)$ or sand $(15 \%$ moisture $)$ that contained each of the seven fungi ( $T$. longibrachiatum, T. koningii, T. harzianum, T. hamatum, T. atroviride, T. viride, or T. spirale) with certain concentrations of conidia as mentioned in each experiments. To prepare the untreated soil/sand, only sterile distilled water was added.

\section{Do Trichoderma Species Attract Coptotermes formosanus? Aggregation-Choice Test}

This study aimed to investigate whether Trichoderma conidia in soil trigger the aggregation preference by termites. Protocols provided by Xiong et al. $(2018,2019)$ were modified to prepare the bioassay arenas. In brief, blocks $(40 \times 40 \times 10 \mathrm{~mm}$ [L by W by $\mathrm{H}]$ ) of soil (sandy clay loam) were made using a plastic mold. A filter paper $($ diameter $=125 \mathrm{~mm}$ ) was placed on the bottom of a Petri dish (diameter $=140 \mathrm{~mm}$, height $=13.5 \mathrm{~mm}$ ) and moistened with $2 \mathrm{~mL}$ sterile distilled water. A soil block treated with Trichoderma conidia $\left(2.5 \times 10^{7}\right.$ conidia/g soil $)$ was placed on one side of the Petri dish, while an untreated soil block was placed on the other side. A piece of balsa wood $(20 \times 20 \times 1 \mathrm{~mm}$ [L by $\mathrm{W}$ by $\mathrm{H}]$ ), a common food source of termites used in the laboratory studies, was placed at the center of each soil block. Fifty termites (45 workers and five soldiers) were released at the center of each Petri dish. The bioassays were maintained in an environmental chamber $\left(25 \pm 1^{\circ} \mathrm{C}\right.$ under total darkness). After $24 \mathrm{~h}$, the percentage of termites in each location (either aggregated in/on each soil block or stationing on the filter paper) was recorded. In total, there were seven aggregation-choice tests, and each test was repeated 24 times (six replicates for each termite colony).

\section{Tunneling-Choice Test}

This study aimed to investigate whether Trichoderma conidia in sand trigger the tunneling preference by termites. Methods provided by Xiong et al. $(2018,2019)$ were modified to prepare the experiments. The bioassay arenas consisted of two square acrylic plates $(156 \times 156 \times 3 \mathrm{~mm}$ [L by W by $\mathrm{H}])$, which were assembled with four narrow edge strips $(156 / 150 \times 3 \times 1.5 \mathrm{~mm}$ [L by $\mathrm{W}$ by $\mathrm{H}]$ ) to create a two-dimensional tunneling chamber. A hole (diameter $=5 \mathrm{~mm}$ ) was made on the central point of the upper plate and the bottom of an acrylic container (diameter $=5 \mathrm{~mm}$, height $=15 \mathrm{~mm}$ ). The upper plate and acrylic container were attached (the holes were connected) and fixed with hot glue. The tunneling arena was divided equally into two parts. One half was filled with $28 \mathrm{~g}$ sand treated with Trichoderma conidia $\left(2.5 \times 10^{7}\right.$ conidia/g sand), and the other half was filled with the same weight of untreated sand. Four pieces of balsa wood $(10 \times 10 \times 1 \mathrm{~mm}[\mathrm{~L}$ by $\mathrm{W}$ by $\mathrm{H}])$ were placed in the corners of the tunneling arena as the food source. The two plates were then held together with binding clips. Fifty termites ( 45 workers and five soldiers) were released into the acrylic container. The arenas 
were placed in an incubator at $25 \pm 1^{\circ} \mathrm{C}$ under total darkness. After 2 days, the arenas were horizontally placed on a LED panel light. A small square of graph paper $(12 \times 12 \mathrm{~mm}, 10$ lines per centimeter) was placed on the bottom plate as the scale, and a high-resolution picture was taken. The area of tunnels made by termites in the Trichoderma-treated and untreated sand was measured using the Image J software (US National Institutes of Health, Bethesda, MD, United States). In total, there were seven tunneling choice tests, and each test was repeated 24 times (six replicates for each termite colony).

\section{Do Trichoderma Species Suppress Termite Pathogen?}

\section{Antagonism Test}

We investigated whether Trichoderma species (T. longibrachiatum, T. harzianum, or T. atroviride) inhibit the growth of M. anisopliae using both dual-culture and fermentation filtrate experiments. In the dual culture experiments, the fungal discs (diameter $=4 \mathrm{~mm}$ ) were obtained by punching the edge of each fungal colony (after 4 days of initial inoculation) using a sterile hole puncher. A fungal disc of $M$. anisopliae was placed at one side of the PDA medium $(10 \mathrm{~mm}$ distance from the edge of the Petri dish), while a fungal disc of each of the three Trichoderma species was placed on the other side. The PDA media with the $M$. anisopliae disc alone was used as the controls. The radial diameter of $M$. anisopliae colonies was measured using a digital caliper until its diameter no longer changed (measurement data unchanged for 3 days). Inhibitory rate was determined using the formula as follows: inhibitory rate $(\%)=[$ (mean radial diameter of $M$. anisopliae in the controls radial diameter of $M$. anisopliae in each antagonism test)/mean radial diameter of $M$. anisopliae in the controls] $\times 100 \%$. Each test was repeated five times.

In the fermentation filtrate tests, the activated mycelial plugs of each Trichoderma species were inoculated to $300 \mathrm{~mL}$ potato dextrose broth (PDB, Guangdong Huankai Microbial Technology Co., Ltd., Guangdong, China) in Erlenmeyer flasks, and were then incubated on a shaker $\left(120 \mathrm{r} / \mathrm{min}, 25 \pm 1^{\circ} \mathrm{C}\right)$ for 10 days. The contents in flask were centrifuged for $5 \mathrm{~min}$ at $47,000 \mathrm{~g}$, and the supernatant was filtered through a $0.22 \mu \mathrm{m}$ membrane filter. The filtered supernatant $(1 \mathrm{~mL})$ or the same amount of sterile distilled water (control) was then mixed with PDA medium $(19 \mathrm{~mL})$. Before solidification, the mixtures $(20 \mathrm{~mL})$ were poured into the Petri dishes (diameter $=90 \mathrm{~mm})$. After the medium was solidified, a fungal disc (diameter $=4 \mathrm{~mm}$ ) of $M$. anisopliae was placed at the center of each medium. The diameter of mycelial growth of $M$. anisopliae was measured until its diameter no longer changed. Inhibitory rate was calculated using the same formula as mentioned in the dual-culture experiments. Each test was repeated five times.

\section{Mortality Test}

This study aimed to investigate whether Trichoderma species protect termites from the infection of $M$. anisopliae. Three Trichoderma species (T. longibrachiatum, T. harzianum, and T. atroviride) that attracted termites (see section "Results") were tested in this and the following experiments. A sterilized filter paper (diameter $=85 \mathrm{~mm}$ ) was placed on the bottom of the Petri dish (diameter $=90 \mathrm{~mm})$. There were eight treatments: treatment 1-4: only conidial suspension of each Trichoderma species (T. longibrachiatum, T. harzianum, or T. atroviride) or $M$. anisopliae $(1 \mathrm{~mL}$ conidial suspension at the concentration of $5 \times 10^{7}$ conidia $/ \mathrm{mL}$ ) was evenly added onto the filter paper (the final concentration of each fungus was $5 \times 10^{7}$ conidia/dish); treatment 5-7: both conidial suspensions of each Trichoderma species (T. longibrachiatum, T. harzianum, or T. atroviride) and $M$. anisopliae $(0.5 \mathrm{~mL}$ conidial suspension for each fungus at the concentration of $1 \times 10^{8}$ conidia/mL) were evenly added onto the filter paper (the final concentration of each fungus was $5 \times 10^{7}$ conidia/dish); and treatment 8 : only sterile distilled water $(1 \mathrm{~mL})$ was evenly added onto the filter paper (controls).

Fifty termites (45 workers and five soldiers) were released into each Petri dish. The bioassays were maintained in an environmental chamber at $25 \pm 1^{\circ} \mathrm{C}$ under total darkness for 20 days. The mortality of termites (termites were considered dead when their body laid sideways or upside-down) in each replicate was recorded each day. Each treatment was repeated 24 times (six replicates for each termite colony).

\section{Do Trichoderma Species Alter the Repellency of Metarhizium anisopliae Against Coptotermes formosanus?}

\section{Aggregation-Choice Test}

This study aimed to investigate whether Trichoderma species alters the repellency of $M$. anisopliae against $C$. formosanus. Similar procedures of the aggregation-choice tests described earlier were used to prepare soil blocks (loamy sand soil) and set the bioassays, but the treated soil blocks contained conidia of Trichoderma species or M. anisopliae alone or together (Table 2) at a final concentration for each fungus of $1 \times 10^{7}$ conidia/g soil. The percentages of termites in each location (aggregated in/on each soil block or stationing on the filter paper) were calculated

TABLE 2 | Aggregation-choice tests to investigate whether Trichoderma species alters the repellency of Metarhizium anisopliae against Coptotermes formosanus.

\begin{tabular}{|c|c|c|c|}
\hline Test & Control soil block & vs. & Treated soil block \\
\hline 1 & Untreated soil & vs. & $\begin{array}{l}\text { Soil only containing conidia of } \\
\text { T. longibrachiatum }\end{array}$ \\
\hline 2 & Untreated soil & vs. & $\begin{array}{l}\text { Soil only containing conidia of } \\
\text { T. harzianum }\end{array}$ \\
\hline 3 & Untreated soil & vs. & $\begin{array}{l}\text { Soil only containing conidia of } \\
\text { T. atroviride }\end{array}$ \\
\hline 4 & Untreated soil & vs. & $\begin{array}{l}\text { Soil only containing conidia of } \\
\text { M. anisopliae }\end{array}$ \\
\hline 5 & Untreated soil & vs. & $\begin{array}{l}\text { Soil containing both conidia of } \\
\text { M. anisopliae and } \\
\text { T. longibrachiatum }\end{array}$ \\
\hline 6 & Untreated soil & vs. & $\begin{array}{l}\text { Soil containing both conidia of } \\
\text { M. anisopliae and T. harzianum }\end{array}$ \\
\hline 7 & Untreated soil & vS. & $\begin{array}{l}\text { Soil containing both conidia of } \\
\text { M. anisopliae and T. atroviride }\end{array}$ \\
\hline
\end{tabular}

The final concentration for each fungus was $1 \times 10^{7}$ conidia/g soil. 
at $12 \mathrm{~h}$. Each choice test was repeated 12 times (three replicates for each termite colony).

\section{Tunneling Non-Choice Test}

This study aimed to investigate the tunneling behaviors of termites in response to sand treated with $M$. anisopliae alone, or M. anisopliae and Trichoderma species together. The bioassay arenas were two-dimensional tunneling chambers as described earlier, but the arena was not divided into two parts. Instead, each tunneling arena was filled with $56 \mathrm{~g}$ sand which (1) only contained each of the four fungi ( $T$. longibrachiatum, T. harzianum, T. atroviride, or $M$. anisopliae) with the final concentration of $1 \times 10^{7}$ conidia/g sand; (2) contained both conidia of Trichoderma species ( $T$. longibrachiatum, $T$. harzianum, or $T$. atroviride) and $M$. anisopliae at the final concentration of $1 \times 10^{7}$ conidia/g sand for each fungus; (3) did not contain any fungal conidia (untreated sand). Fifty termites (45 workers and five soldiers) were released to the acrylic container. After 7 days, the areas of tunnels were measured as described earlier. In addition, the number of termites alive in each arena was recorded, and the excavation volume of sand was estimated by weighing the sand that was transported into the release chamber. Each treatment was repeated 12 times (three replicates for each termite colony).

\section{Statistical Analyses}

For the aggregation-choice tests, the log-ratio transformation was conducted to make the compositional data (percentages) independent (Kucera and Malmgren, 1998; Wang et al., 2015; Xiong et al., 2018). The transformed data were compared using two-way analysis of variance (ANOVA) with termite colony as the random effect and location as the fixed effect. For the tunneling tests, the areas of tunnels in the treated and untreated sand in the choice tests, and the mortality, weight of excavated sand, and tunnel area in the non-choice tests were analyzed using two-way ANOVA with colony group as the random effect and the treatment as the fixed effect. For the antagonism tests, the inhibitory rates of the three Trichoderma species against M. anisopliae were compared using one-way ANOVA. For the mortality tests, the mortality of termites was compared using two-way ANOVA with termite colony as the random effect and treatment as the fixed effect. In addition, the median lethal time $\left(\mathrm{LT}_{50}\right)$ of termites in each treatment was calculated and compared using the probit analysis (IBM SPSS Statistics version 22.0, Chicago, IL, United States). Tukey's HSD tests were conducted for multiple comparisons after each ANOVA at $\alpha=0.05$.

\section{RESULTS}

\section{Do Trichoderma Species Attract Coptotermes formosanus? Aggregation-Choice Tests}

The mean survival of termites was $>95 \%$ in the aggregationchoice test. Significantly more termites preferred to aggregate in/on the soil block containing conidia of T. longibrachiatum, T. harzianum, T. hamatum, T. atroviride, T. viride, or T. spirale compared with the untreated soil blocks (Table 3). However, there was no significant difference in percentage of termites between soil blocks treated with $T$. koningii and untreated ones (Table 3).

\section{Tunneling-Choice Test}

Termites produced significantly larger tunnels in sand treated with $T$. longibrachiatum or $T$. koningii than that in untreated sand. However, the areas of tunnels were similar in untreated sand and sand treated with $T$. harzianum, $T$. hamatum, T. atroviride, T. viride, or T. spirale (Table 4).

\section{Do Trichoderma Species Suppress Termite Pathogen? Antagonism Test}

In the dual-culture tests, the average inhibitory rates of T. longibrachiatum, T. harzianum, and T. atroviride were 71.0, 64.8 , and $60.7 \%$, respectively. T. longibrachiatum exhibited a significantly stronger inhibitory effect against $M$. anisopliae, as compared with $T$. harzianum and $T$. atroviride $(F=29.48$, $\mathrm{df}=2, P<0.0001 ;$ Figure 1A). In the fermentation filtrate tests, the average inhibitory rates of $T$. longibrachiatum, T. harzianum, and T. atroviride were 81.5, 74.0, and $66.9 \%$,

TABLE 3 | Percentage (mean \pm SE) of termites aggregated in the Trichoderma-treated or untreated soil blocks or stationing on the Petri dishes.

\begin{tabular}{|c|c|c|c|c|c|c|c|}
\hline \multirow[t]{2}{*}{ Test } & \multirow[t]{2}{*}{ Treated block } & \multirow[t]{2}{*}{ Petri dish } & \multirow[t]{2}{*}{ Untreated block } & \multicolumn{3}{|c|}{ Statistical result } & \multirow[t]{2}{*}{ Effect } \\
\hline & & & & $F$ & d.f. & $P$ & \\
\hline T. longibrachiatum & $67.33 \pm 5.06 \mathrm{a}$ & $9.88 \pm 1.34 b$ & $22.79 \pm 5.05 b$ & 38.35 & 2,60 & $<0.0001$ & Attractive \\
\hline T. koningii & $44.88 \pm 5.97 \mathrm{a}$ & $21.33 \pm 2.47 b$ & $33.79 \pm 5.08 \mathrm{ab}$ & 4.00 & 2,60 & 0.0235 & N.A. \\
\hline T. harzianum & $65.25 \pm 5.58 \mathrm{a}$ & $12.17 \pm 2.22 b$ & $22.58 \pm 4.84 b$ & 38.66 & 2,60 & $<0.0001$ & Attractive \\
\hline T. hamatum & $70.00 \pm 4.45 a$ & $11.00 \pm 1.71 b$ & $19.00 \pm 4.09 b$ & 62.33 & 2,60 & $<0.0001$ & Attractive \\
\hline T. atroviride & $64.08 \pm 5.12 \mathrm{a}$ & $19.50 \pm 3.56 b$ & $16.42 \pm 3.84 b$ & 59.12 & 2,60 & $<0.0001$ & Attractive \\
\hline T. viride & $51.17 \pm 5.45 \mathrm{a}$ & $22.42 \pm 2.48 b$ & $26.42 \pm 4.86 b$ & 7.20 & 2,60 & 0.0016 & Attractive \\
\hline T. spirale & $81.42 \pm 3.12 \mathrm{a}$ & $8.00 \pm 1.52 b$ & $10.58 \pm 2.46 b$ & 135.64 & 2,60 & $<0.0001$ & Attractive \\
\hline
\end{tabular}

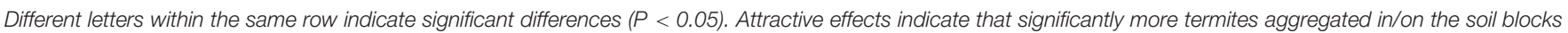

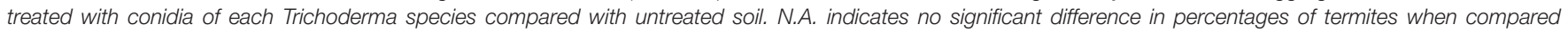
between Trichoderma-treated and untreated soil blocks. 
TABLE 4 | Areas of tunnels (mean \pm SE) produced in Trichoderma-treated and untreated sand.

\begin{tabular}{|c|c|c|c|c|c|c|}
\hline \multirow[t]{2}{*}{ Test } & \multirow[t]{2}{*}{ Treated sand $\left(\mathrm{mm}^{2}\right)$} & \multirow[t]{2}{*}{ Untreated sand $\left(\mathrm{mm}^{2}\right)$} & \multicolumn{3}{|c|}{ Statistical result } & \multirow[t]{2}{*}{ Effect } \\
\hline & & & $\boldsymbol{F}$ & d.f. & $P$ & \\
\hline T. longibrachiatum & $1129.96 \pm 72.28 a$ & $706.22 \pm 58.08 b$ & 23.93 & 1,40 & $<0.0001$ & Enhanced \\
\hline T. koningii & $1163.89 \pm 47.27 a$ & $908.31 \pm 89.60 b$ & 11.56 & 1,40 & 0.0015 & Enhanced \\
\hline T. harzianum & $1030.26 \pm 77.14 a$ & $1043.34 \pm 60.13 a$ & 0.02 & 1,40 & 0.8816 & N.A. \\
\hline T. hamatum & $881.38 \pm 62.82 \mathrm{a}$ & $862.43 \pm 57.18 a$ & 0.06 & 1,40 & 0.8011 & N.A. \\
\hline T. atroviride & $1027.45 \pm 84.75 a$ & $937.84 \pm 54.04 a$ & 0.97 & 1,40 & 0.3313 & N.A. \\
\hline T. viride & $929.92 \pm 74.52 \mathrm{a}$ & $837.54 \pm 60.25 a$ & 1.00 & 1,40 & 0.3232 & N.A. \\
\hline T. spirale & $811.14 \pm 55.60 a$ & $959.28 \pm 71.32 a$ & 2.64 & 1,40 & 0.1121 & N.A. \\
\hline
\end{tabular}

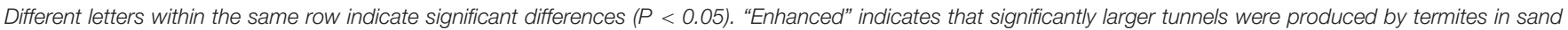

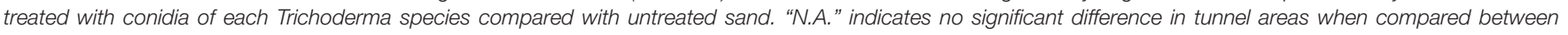
Trichoderma-treated and untreated sand.

A

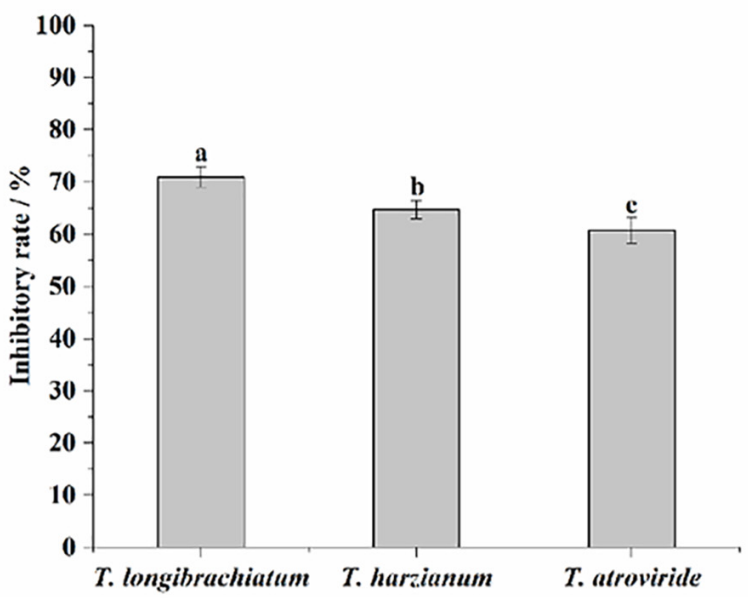

B

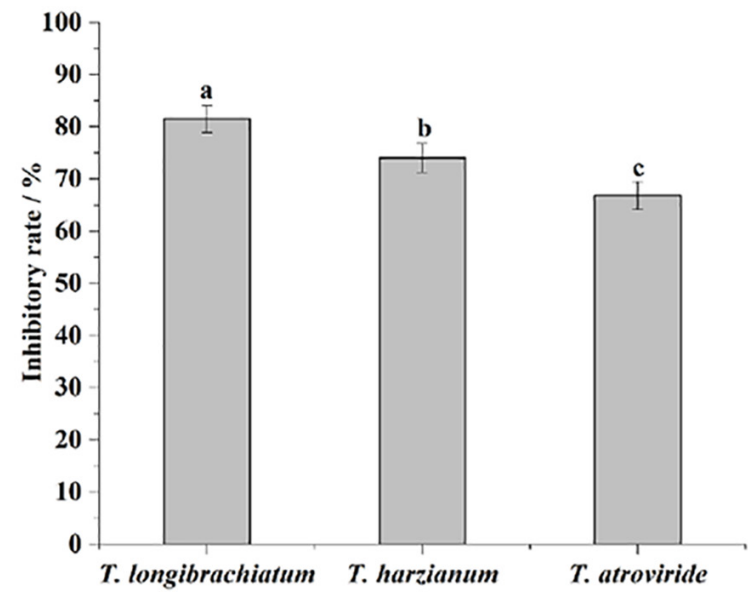

FIGURE 1 | Inhibitory rates of the three Trichoderma species against Metarhizium anisopliae in the dual-culture tests (A) and fermentation filtrate experiments (B). Different letters indicate significantly different $(P<0.05)$

respectively. The inhibitory rate of $T$. longibrachiatum against $M$. anisopliae was significantly higher than that of $T$. harzianum, and both were significantly higher than that of $T$. atroviride $(F=37.41$, $\mathrm{df}=2, P<0.0001$; Figure 1B).

\section{Mortality Test}

From day 4 to 14, the mortality of termites exposed to $M$. anisopliae alone was significantly higher than in the other treatments (Figure 2; statistical results are shown in Supplementary Table S1). From day 17 to 20, however, the mortality of termites exposed to $M$. anisopliae alone was not significantly different from termites that were exposed to both Trichoderma species and M. anisopliae (Figure $\mathbf{2}$ and Supplementary Table S1), but all of them had significantly higher mortality compared with termites exposed to Trichoderma conidia alone or distilled water (controls). In addition, for the four termite colonies, the $\mathrm{LT}_{50}$ value of termites exposed to M. anisopliae alone was significantly lower than termites exposed to both M. anisopliae and Trichoderma species (Table 5).

\section{Do Trichoderma Species Alter the Repellency of Metarhizium anisopliae Against Coptotermes formosanus? Aggregation-Choice Test}

The mean survival of termites was $>94 \%$ in each aggregationchoice test. Significantly fewer termites were found in/on the soil blocks treated with the conidia of $M$. anisopliae compared with untreated ones (Table 6), indicating a repellent effect of M. anisopliae against termites. However, percentage of termites aggregated in/on the soil treated with both $M$. anisopliae and T. longibrachiatum or T. harzianum was not significantly different from the untreated ones (Table 6).

\section{Tunneling Non-Choice Test}

Termites had significantly higher mortality when exposed to sand treated with conidia of $M$. anisopliae (either alone or together with $T$. harzianum or $T$. atroviride species) compared with the sand treated with conidia of $T$. harzianum alone $(F=5.94, \mathrm{df}=7,64, P<0.0001$; Figure 3A). In addition, significantly less weight of excavated sand 


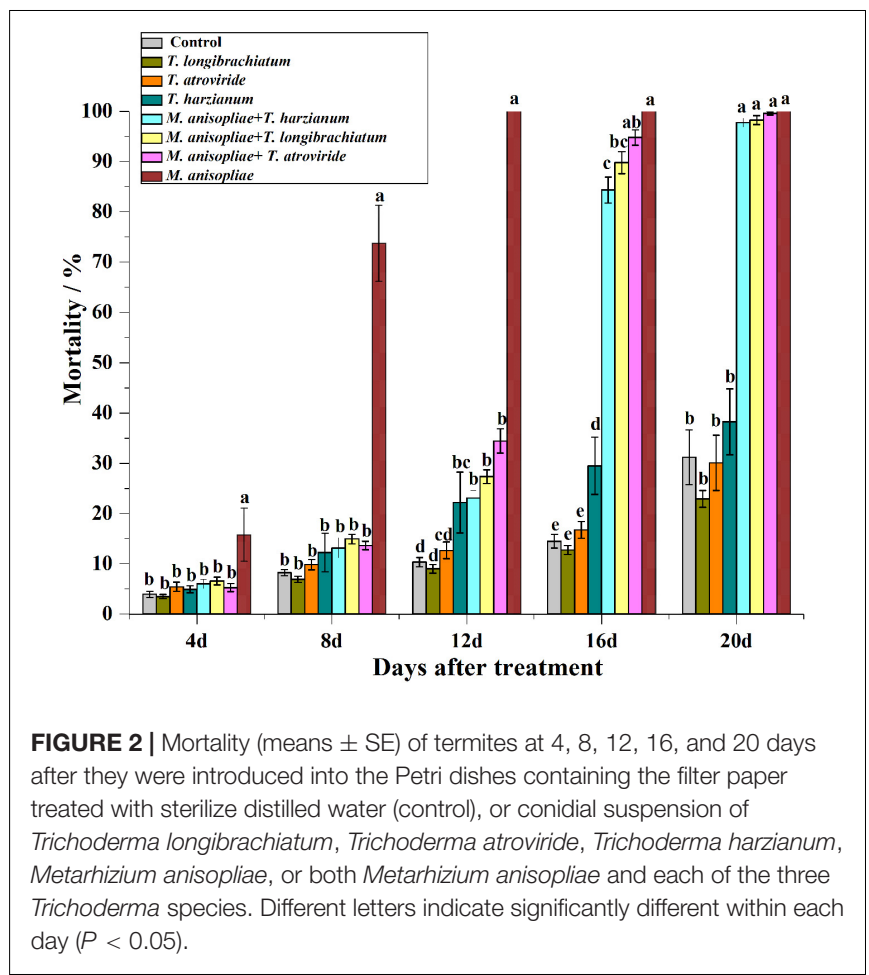

$(F=66.62, \mathrm{df}=7,64, P<0.0001 ;$ Figure 3B $)$ and area of tunnels $(F=39.80$, df $=7,64, P<0.0001$; Figure $3 \mathrm{C}$ ) were found when the sand was treated with conidia of M. anisopliae (either alone or together with Trichoderma species) compared with the untreated sand or sand treated with each Trichoderma species alone.

\section{DISCUSSION}

Our study showed that Trichoderma species in substrates (soil or sand) generally attracted C. formosanus. In addition, some Trichoderma species benefited termites by inhibiting M. anisopliae. Interestingly, T. longibrachiatum and T. harzianum altered the repellency of $M$. anisopliae against termites. These results enhance the understanding of the complex interactions among lower subterranean termites and various fungi living in their habitats (Figure 4).

Esenther et al. (1961) were the first reported that the brown-rotting fungus, Gloeophyllum trabeum (Pers.) attracted subterranean termites $R$. flavipes, Reticulitermes virginicus (Banks), and Nasutitermes columbicus (Holmgren). After that, various wood-rotting fungi including Phanerochaete chrysosporium (Burdsall) and Marasmiellus troyanus (Murrill) (Amburgey, 1979; Ohmura et al., 1995; Cornelius et al., 2002, 2004, 2012), as well as blue-staining fungi including Ophiostoma ips (Rumb) and Leptographium terebrantis (Barras) (Little et al., 2012a,b, 2013; Clay et al., 2017), were reported to enhance aggregation and feeding activities of subterranean termites. These fungi may provide the chemical cues for termites to locate and make tunnels toward food sources. For example, the chemical (Z,Z,E)-3,6,8-dodecatrien-1-ol produced by G. trabeum has been identified as the major component of trail-following pheromone in various termite species such as Reticulitermes lucifugus grassei Clément, Reticulitermes santonensis Feytaud, and Reticulitermes hesperus Banks (Matsumura et al., 1976; Laduguie et al., 1994; Wobst et al., 1999; Saran et al., 2007). In addition, the presence of wood-rotting fungi could bring nutritional benefits to termites by providing proteins and improving their ability to metabolize lignocellulose (Waller and La Fage, 1987; Brune and Dietrich, 2015; Peterson and Scharf, 2016). On the contrary, termites may negatively affect wood-rotting fungi. Martin and Bulmer (2018) reported that subterranean termites can produce $\beta$-1,3-glucanases and have antifungal properties which suppress the growth of G. trabeum and P. chrysosporium (Burdsall).

In the present study, we found that almost all tested Trichoderma species (except T. koningii) triggered termite aggregation. These results indicate that fungi in the genus Trichoderma may exert generally attractive effects on C. formosanus. This attractive effect might be concentrationdependent, because $T$. atroviride with the concentration of $2.5 \times 10^{7}$ conidia/g soil significantly attracted termites (Table 3), whereas the same fungus with the concentration of $1 \times 10^{7}$ conidia/g soil showed no significant attractive effect (Table 6). However, the attractiveness of $T$. longibrachiatum and $T$. harzianum were consistent at both concentrations. Interestingly, T. harzianum, T. hamatum, T. atroviride, T. viride, and $T$. spirale were attractive in the aggregation-choice tests but not active in the tunneling-choice tests. After releasing into open-air areas of the aggregation-choice tests, volatile chemicals produced by these Trichoderma species may elicit the olfactory responses of termites, and cause the aggregation preference. During tunnel excavating, however, termites contact the substrate with their cuticles and carry the sand particles with mouthparts. During these processes, haptic and/or gustatory cues may be needed to trigger tunneling preferences. Su (2005) reported that $C$. formosanus and $R$. flavipes made tunnels toward the wood discs infested with $G$. trabeum. To be detected by termites, the attracting chemicals produced by $G$. trabeum should be water-soluble and can "permeate through wet sand" (Su, 2005). Likewise, our study showed that termites produced significantly larger areas of tunnels in sand treated with T. longibrachiatum or T. koningii. These fungi may produce water-soluble chemicals, which provide haptic and/or gustatory cues to enhance the tunneling activities of termites. It would be valuable to investigate the underlying mechanisms of the aggregation and tunneling preferences triggered by different Trichoderma species.

Biedermann and Vega (2020) reviewed the evolution of insect-fungus mutualisms, which were driven by exchanged services such as nutrition and protection. The aggregation and tunneling preferences might be a result of positive selection because Trichoderma species benefit termites in many aspects. Mankowski et al. (1998) reported that consuming wood infested with $T$. viride increased the number of protozoa in the gut of Zootermopsis angusticollis (Hagen). Jayasimha and Henderson (2007) reported that Trichoderma 
TABLE 5 | Median lethal time ( $\left.\mathrm{LT}_{50}\right)$ of termites exposed to conidia of Metarhizium anisopliae alone, or both conidia of Metarhizium anisopliae and each Trichoderma species.

\begin{tabular}{|c|c|c|c|c|c|}
\hline Colony & Treatment & $n$ & $\mathbf{L T}_{50}$ (days) & Regression equation & $\chi^{2}(\mathrm{df})$ \\
\hline \multirow[t]{4}{*}{1} & M. anisopliae alone & 300 & $5.55(5.25-5.84)$ & $y=-4.93+0.89 x$ & $673.34(118)$ \\
\hline & M. anisopliae and T. longibrachiatum & 300 & $11.84(11.52-12.17)$ & $y=-5.56+0.47 x$ & $425.02(118)$ \\
\hline & M. anisopliae and T. harzianum & 300 & $12.83(12.50-13.18)$ & $y=-5.17+0.40 x$ & $393.13(118)$ \\
\hline & M. anisopliae and T. atroviride & 300 & $11.88(11.51-12.24)$ & $y=-6.04+0.51 x$ & $596.45(118)$ \\
\hline \multirow[t]{4}{*}{2} & M. anisopliae alone & 300 & $5.57(5.14-5.98)$ & $y=-4.44+0.80 x$ & $1197.59(118)$ \\
\hline & M. anisopliae and T. Iongibrachiatum & 300 & $12.74(12.39-13.09)$ & $y=-5.10+0.40 x$ & $418.70(118)$ \\
\hline & M. anisopliae and T. harzianum & 300 & $12.70(12.31-13.09)$ & $y=-6.50+0.51 x$ & $677.41(118)$ \\
\hline & M. anisopliae and T. atroviride & 300 & $11.11(10.79-11.42)$ & $y=-7.01+0.63 x$ & $565.57(118)$ \\
\hline \multirow[t]{4}{*}{3} & M. anisopliae alone & 300 & $6.28(5.79-6.75)$ & $y=-4.48+0.71 x$ & $1394.21(118)$ \\
\hline & M. anisopliae and T. longibrachiatum & 300 & $12.32(11.98-12.67)$ & $y=-5.22+0.42 x$ & $427.70(118)$ \\
\hline & M. anisopliae and T. harzianum & 300 & $12.60(12.20-13.00)$ & $y=-4.91+0.39 x$ & $520.14(118)$ \\
\hline & M. anisopliae and T. atroviride & 300 & $11.70(11.33-12.07)$ & $y=-5.36+0.46 x$ & $544.88(118)$ \\
\hline \multirow[t]{4}{*}{4} & M. anisopliae alone & 300 & $7.21(6.93-7.49)$ & $y=-6.51+0.90 x$ & $621.04(118)$ \\
\hline & M. anisopliae and T. Iongibrachiatum & 300 & $13.30(12.96-13.66)$ & $y=-5.10+0.38 x$ & $393.44(118)$ \\
\hline & M. anisopliae and T. harzianum & 300 & $13.75(13.37-14.15)$ & $y=-5.26+0.38 x$ & $461.06(118)$ \\
\hline & M. anisopliae and T. atroviride & 300 & $11.44(11.10-11.78)$ & $y=-6.19+0.54 x$ & $543.82(118)$ \\
\hline
\end{tabular}

TABLE 6 | Percentage (mean \pm SE) of termites aggregated in/on the treated (containing conidia of Trichoderma species or Metarhizium anisopliae alone or together) or untreated soil blocks, or stationing on the Petri dishes.

\begin{tabular}{|c|c|c|c|c|c|c|c|}
\hline \multirow[t]{2}{*}{ Test } & \multirow[t]{2}{*}{ Treated block } & \multirow[t]{2}{*}{ Petri dish } & \multirow[t]{2}{*}{ Untreated block } & \multicolumn{2}{|c|}{ Statistical result } & \multirow[b]{2}{*}{$P$} & \multirow[t]{2}{*}{ Effect } \\
\hline & & & & $\boldsymbol{F}$ & d.f. & & \\
\hline T. longibrachiatum alone & $64.14 \pm 4.16 \mathrm{a}$ & $9.66 \pm 1.24 \mathrm{c}$ & $26.20 \pm 4.19 b$ & 43.10 & 2,10 & $<0.0001$ & Attractive \\
\hline T. harzianum alone & $62.20 \pm 5.22 a$ & $22.89 \pm 4.11 b$ & $14.91 \pm 2.39 b$ & 22.00 & 2,10 & $<0.0001$ & Attractive \\
\hline T. atroviride alone & $51.61 \pm 6.23 a$ & $12.77 \pm 3.97 b$ & $35.62 \pm 4.86 a b$ & 22.76 & 2,10 & $<0.0001$ & N.A. \\
\hline M. anisopliae and T. longibrachiatum & $42.62 \pm 6.84 a$ & $8.74 \pm 0.90 b$ & $48.64 \pm 6.89 a$ & 20.32 & 2,10 & $<0.0001$ & N.A. \\
\hline M. anisopliae and T. harzianum & $25.87 \pm 7.04 a$ & $7.95 \pm 1.56 b$ & $66.18 \pm 7.29 a$ & 47.78 & 2,10 & $<0.0001$ & N.A. \\
\hline M. anisopliae and T. atroviride & $22.30 \pm 4.01 b$ & $12.14 \pm 1.85 c$ & $65.56 \pm 4.10 a$ & 56.80 & 2,10 & $<0.0001$ & Repellent \\
\hline M. anisopliae alone & $15.00 \pm 3.20 b$ & $15.09 \pm 2.89 b$ & $65.95 \pm 4.97 a$ & 25.72 & 2,10 & $<0.0001$ & Repellent \\
\hline
\end{tabular}

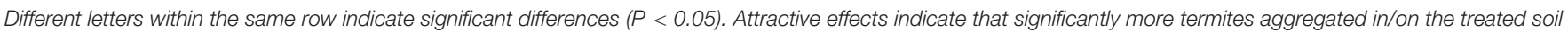
blocks compared with untreated ones. Repellent effects indicate that significantly fewer termites aggregated in/on the treated soil blocks compared with untreated ones. N.A. indicates no significant difference in percentages of termites when compared between treated and untreated soil blocks.

species isolated from the cuticles and/or guts of C. formosanus suppressed the growth of G. trabeum, and therefore may help termites to compete for cellulose. Our study also showed that Trichoderma species play a role in the disease-defending processes of termites, because the three tested Trichoderma species not only suppressed the growth of M. anisopliae in the antagonism tests, but also significantly delayed the lethal effects of $M$. anisopliae in the mortality tests. Our study provides a novel example of environmental fungi associated with termites that reduce epizootic events. Likewise, some recent studies showed that Streptomyces spp. isolated from the gut and nest material of termites inhibited M. anisopliae under both in vivo and in vitro conditions (Chouvenc et al., 2013; Arango et al., 2016). Chouvenc et al. (2011) reviewed researches on biological control of termites in the past 50 years. Although many studies showed the potential of biological control as "environmentally friendly methods to control termites," there is "little evidence to support practical applications in the field" (Chouvenc et al., 2011). The presence of Trichoderma spp. and Streptomyces spp. in the habitats of termites, which antagonize entomopathogenic fungi such as M. anisopliae, may partially explain the failure of termite biological control under field conditions.

In our mortality tests, the three tested Trichoderma species did not completely protect termites from the lethal effect of $M$. anisopliae, because the mortality of termites exposed to both conidia of Trichoderma species and M. anisopliae was not significantly different from $M$. anisopliae alone after 16 days. It is important to note that here a relatively high concentration of M. anisopliae was introduced. M. anisopliae produces various enzymes (e.g., proteases, chitinases, and lipases) and toxins (e.g., destruxins) that cause the death of insect hosts (Hu et al., 2006; Schrank and Vainstein, 2010). Although Trichoderma species can inhibit $M$. anisopliae, they may not be able to inactivate the enzymes and toxins produced by M. anisopliae, which may eventually cause the death of termites. In the field soils, the concentrations of $M$. anisopliae conidia are variable. Rath et al. (1992) isolated M. anisopliae strains from 419 samples of pasture soil in Tasmania, and found that the density for each strain was ranging from $1 \times 10^{2}$ to $5 \times 10^{5}$ colony forming units (cfu) $\mathrm{g}^{-1}$ soil. Nishi and Sato (2019) reported that the 
A

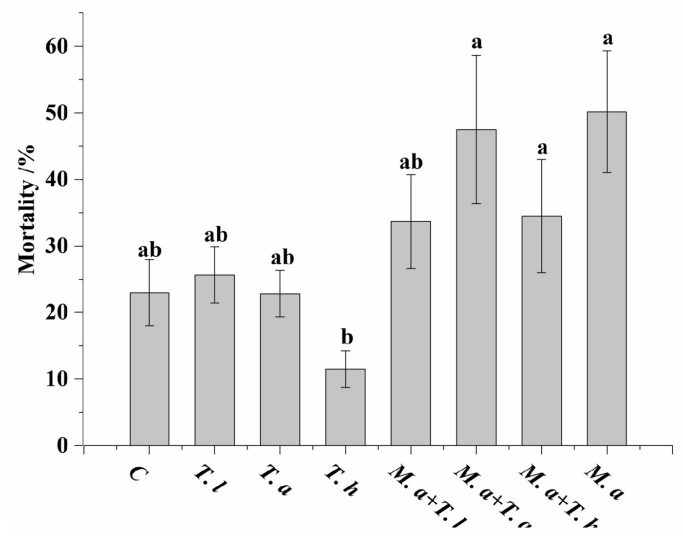

B
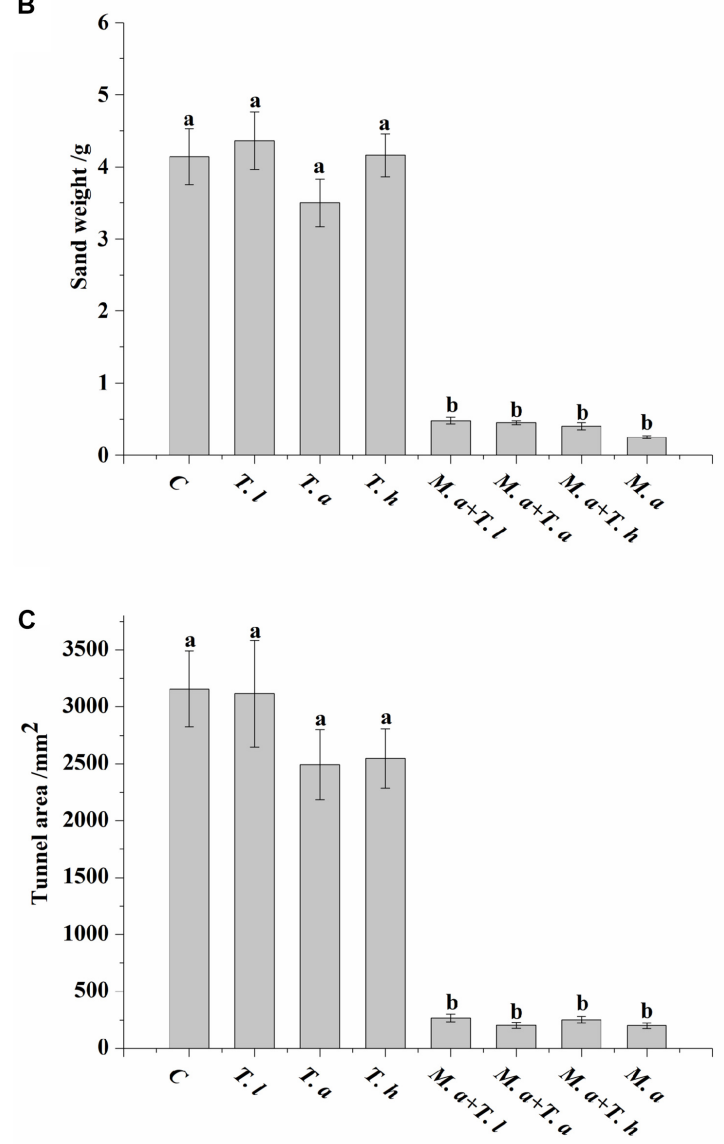

FIGURE 3 | Mortality of termite (A), weight of sand transported into the release chamber (B), and area of tunnels produced by termites (C) are shown as mean \pm SE. Different letters indicate significantly differences $(P<0.05)$. $\mathrm{C}=$ control sand (sand treated with sterile distilled water); $\mathrm{T}$. I = sand treated with conidia of Trichoderma longibrachiatum; $T . h=$ sand treated with conidia of Trichoderma harzianum; T. a = sand treated with conidia of Trichoderma atroviride; $M . a+T . I=$ sand treated with both conidia of Metarhizium anisopliae and Trichoderma longibrachiatum; M. $a+T . h=$ sand treated with both conidia of Metarhizium anisopliae and Trichoderma harzianum; M. $a+T . a=$ sand treated with both conidia of Metarhizium anisopliae and Trichoderma atroviride; $M . a$ = sand treated with conidia of Metarhizium anisopliae.

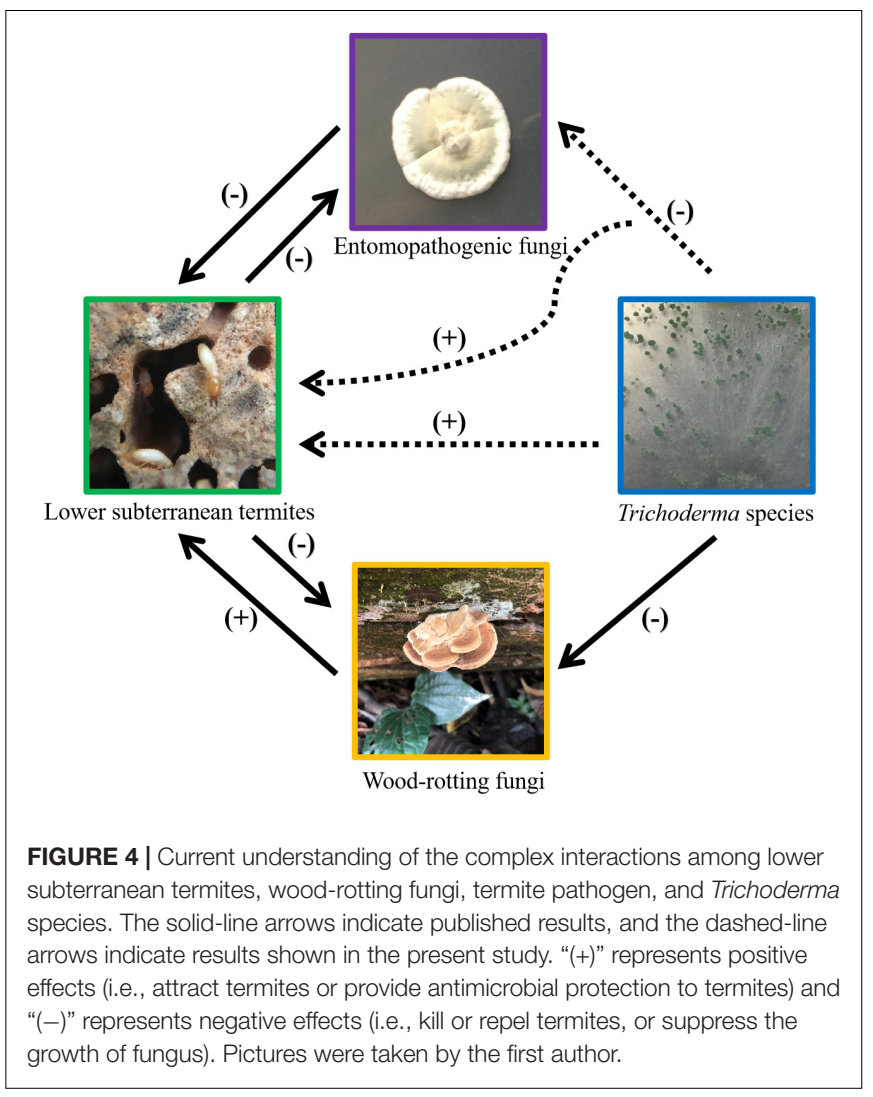

density of Metarhizium spp. in the rhizospheres of wild plants can reach to $4.2 \times 10^{6} \mathrm{cfu} \mathrm{g}^{-1}$ dried soil. Weiser and Matha (1986) reported that the local densities of $M$. anisopliae can be very high because one corpse of infected insects can produce and release $\sim 10^{10}$ conidia in soil. One potential limitation of this study is that we only tested one conidial concentration of $M$. anisopliae and/or Trichoderma species. Since the field densities of these fungi may vary with habitats and environmental conditions, it is important to test the protective effect of Trichoderma species on termites at different conidial concentrations and Trichoderma/Metarhizium ratios in future studies.

Termites also have evolved many other defense mechanisms to reduce the risk of epizootic events (Myles, 2002; Liu et al., 2015, 2019a,b; Peterson and Scharf, 2016; Davis et al., 2018). Previous studies have shown that termites can produce various antimicrobial agents including termicin and spinigerin (Lamberty et al., 2001; Bulmer et al., 2009; Hamilton et al., 2011). In addition, behavioral immunity such as mutual grooming can effectively remove conidia of entomopathogenic fungi from cuticles and therefore protect termites (Shimizu, 2003; Yanagawa et al., 2005; Yanagawa and Shimizu, 2007). Many termites can also avoid to aggregate or make tunnels in the substrate containing harmful fungi (Staples and Milner, 2000; Mburu et al., 2009, 2011; Hussain et al., 2010; Sun et al., 2014). This "spatial avoidance" was also observed in our study, because $M$. anisopliae-treated sand significantly decreased aggregation and tunneling activities of termites. Interestingly, the presence of T. longibrachiatum or T. harzianum altered the repellent effects of $M$. anisopliae against 
termites in the aggregation-choice tests. The results of this study suggest that these Trichoderma species may increase the contact between termites and pathogens, and therefore negatively affect the health and survival of termites. The volatiles associated with these Trichoderma species likely disturb the olfactory responses of termite reacting to the $M$. anisopliae conidia. Screening such volatiles would help to break the spatial avoidance of entomopathogenic fungi by termites.

\section{CONCLUSION}

Previous studies have shown complex interactions among termites and environmental microbes (i.e., wood-rotting fungi, blue-staining fungi, and entomopathogenic fungi). In the present study, nearly all Trichoderma species tested significantly increased aggregation of $C$. formosanus. Trichoderma species had antagonistic effects against $M$. anisopliae, and protected termites from infection. Although M. anisopliae conidia repelled termites, the presence of $T$. longibrachiatum or T. harzianum reduced the repellency of $M$. anisopliae against termites.

\section{DATA AVAILABILITY STATEMENT}

The raw data supporting the conclusions of this manuscript will be made available by the authors, without undue reservation, to any qualified researcher.

\section{ETHICS STATEMENT}

Ethical review and approval was not required for the animal study because the animals used in this study were termites, a very destructive pest. Distress to the termites during their collection in the field and their transport to the laboratory was minimized as much as possible. In the laboratory, colonies were maintained

\section{REFERENCES}

Amburgey, T. L. (1979). Review and checklist of the literature on interactions between wood-inhabiting fungi and subterranean termites: 1960-1978. Sociobiology 4, 279-296. doi: 10.1017/S0009840X00010131

Arango, R. A., Carlson, C. M., Currie, C. R., Mcdonald, B. R., Book, A. J., Green, F., et al. (2016). Antimicrobial activity of actinobacteria isolated from the guts of subterranean termites. Environ. Entomol. 45, 1-9. doi: 10.1093/ee/nvw126

Biedermann, P. H., and Vega, F. E. (2020). Ecology and evolution of insectfungus mutualisms. Ann. Rev. Entomol. 65, 431-455. doi: 10.1146/annurevento-011019-024910

Brune, A., and Dietrich, C. (2015). The gut microbiota of termites: digesting in the light of ecology and evolution. Ann. Rev. Microbiol. 69, 145-166. doi: 10.1146/ annurev-micro-092412-155715

Bulmer, M. S., Bachelet, I., Raman, R., Rosengaus, R. B., and Sasisekharan, R. (2009). Targeting an antimicrobial effector function in insect immunity as a pest control strategy. Proc. Natl. Acad. Sci. U.S.A. 106, 12652-12657. doi: 10. 1073/pnas.0904063106

Carrero-Carrón, I., Trapero-Casas, J. L., Olivares-García, C., Monte, E., Hermosa, R., and Jiménez-Díaz, R. M. (2016). Trichoderma asperellum is effective for biocontrol of Verticillium wilt in olive caused by the defoliating pathotype under suitable conditions, thereby maximizing their welfare and survival. After the end of the experiments, colonies were kept in the laboratory until their natural death.

\section{AUTHOR CONTRIBUTIONS}

$\mathrm{CaW}$ and $\mathrm{ChW}$ conceived and designed the experiments. ChW and HX performed the experiments. ChW was mainly responsible for analyzing the data and writing the manuscript. $\mathrm{CaW}, \mathrm{XW}$, and JW were involved in the revision of the manuscript.

\section{FUNDING}

This work was supported by the National Natural Science Foundation of China (31500530).

\section{ACKNOWLEDGMENTS}

We sincerely thank Shiping Liang, Wenquan Qin, and Zhengya Jin (College of Forestry and Landscape Architecture, South China Agricultural University) for the assistance of termite collecting and bioassay preparation. We also sincerely thank Dr. Erike Nielsin (College of Forestry and Landscape Architecture, South China Agricultural University) and the two reviewers for their valuable comments and suggestions on the manuscript.

\section{SUPPLEMENTARY MATERIAL}

The Supplementary Material for this article can be found online at: https://www.frontiersin.org/articles/10.3389/fmicb. 2020.00653/full\#supplementary-material

of Verticillium dahliae. Crop. Prot. 88, 45-52. doi: 10.1016/j.cropro.2016.0 5.009

Chouvenc, T., Efstathion, C. A., Elliott, M. L., and Su, N. Y. (2013). Extended disease resistance emerging from the faecal nest of a subterranean termite. Proc. Biol. Sci. 280:20131885. doi: 10.1098/rspb.2013.1885

Chouvenc, T., Su, N. Y., and Grace, J. K. (2011). Fifty years of attempted biological control of termites - analysis of a failure. Biol. Control 59, 69-82. doi: 10.1016/j. biocontrol.2011.06.015

Clay, N. A., Little, N., and Riggins, J. J. (2017). Inoculation of ophiostomatoid fungi in loblolly pine trees increases the presence of subterranean termites in fungal lesions. Arthropod Plant Interact. 11, 213-219. doi: 10.1007/s11829-016-94 73-5

Cornelius, M. L., Bland, J. M., Daigle, D. J., Williams, K. S., Lovisa, M. P., Connick, W. J., et al. (2004). Effect of a lignin-degrading fungus on feeding preferences of Formosan subterranean termite (Isoptera: Rhinotermitidae) for different commercial lumber. J. Econ. Entomol. 97, 1025-1035. doi: 10.1093/jee/97.3. 1025

Cornelius, M. L., Daigle, D. J., Connick, W. J., Parker, A., and Wunch, K. (2002). Responses of Coptotermes formosanus and Reticulitermes flavipes (Isoptera: Rhinotermitidae) to three types of wood rot fungi cultured on different substrates. J. Econ. Entomol. 95, 121-128. doi: 10.1603/0022-0493-95.1.121 
Cornelius, M. L., Williams, K. S., Lovisa, M. P., and Daigle, D. J. (2012). Aggregation and feeding behavior of the Formosan subterranean termite (Isoptera: Rhinotermitidae) on wood decayed by three species of wood rot fungi. Sociobiology 59, 667-680. doi: 10.1038/s41598-018-32721-7

Davis, H. E., Meconcelli, S., Radek, R., and McMahon, D. P. (2018). Termites shape their collective behavioural response based on stage of infection. Sci. Rep. 8:14433. doi: 10.1038/s41598-018-32721-7

Denier, D., and Bulmer, M. S. (2015). Variation in subterranean termite susceptibility to fatal infections by local Metarhizium soil isolates. Insect. Soc. 62, 219-226. doi: 10.1007/s00040-015-0394-6

Esenther, G. R., Allen, T. C., Casida, J. E., and Shenefelt, R. D. (1961). Termite attractant from fungus-infected wood. Science 134, 50-50. doi: 10.1126/science. 134.3471 .50

Govarthanan, M., Mythili, R., Selvankumar, T., Kamala-Kannan, S., and Kim, H. (2018). Myco-phytoremediation of arsenic-and lead-contaminated soils by, Helianthus annuus, and wood rot fungi, Trichoderma, sp. isolated from decayed wood. Ecotox. Environ. Saf. 151, 279-284. doi: 10.1016/j.ecoenv.2018. 01.020

Hamilton, C., Lay, F., and Bulmer, M. S. (2011). Subterranean termite prophylactic secretions and external antifungal defenses. J. Insect. Physiol. 57, 1259-1266. doi: 10.1016/j.jinsphys.2011.05.016

Harman, G. E., Howell, C. R., Viterbo, A., Chet, I., and Lorito, M. (2004). Trichoderma spp. - opportunistic avirulent plant symbionts. Nat. Rev. Microbiol. 2, 43-56. doi: 10.1038/nrmicro797

Hu, Q. B., Ren, S. X., Wu, J. H., Chang, J. M., and Musa, P. D. (2006). Investigation of destruxin A and B from 80 Metarhizium strains in China, and the optimization of cultural conditions for the strain MaQ10. Toxicon 48, 490-498. doi: 10.1016/j.toxicon.2006.06.018

Hussain, A., Tian, M. Y., He, Y. R., Bland, J. M., and Gu, W. X. (2010). Behavioral and electrophysiological responses of Coptotermes formosanus Shiraki towards entomopathogenic fungal volatiles. Biol. Control 55, 166-173. doi: 10.1016/j. biocontrol.2010.08.009

Jayasimha, P., and Henderson, G. (2007). Fungi isolated from integument and guts of Coptotermes formosanus and their antagonistic effect on Gleophyllum trabeum. Ann. Entomol. Soc. Am. 100, 703-710. doi: 10.1603/001387462007100

Jones, W. E., Grace, J. K., and Tamashiro, M. (1996). Virulence of seven isolates of Beauveria bassiana and Metarhizium anisopliae to Coptotermes formosanus (Isoptera: Rhinoterrnitidae). Environ. Entomol. 25, 481-487. doi: 10.1093/ee/ 25.2.481

Kath, J., Dias-Arieira, C. R., Homiak, J. A., Ferreira, J. C. A., and Cardoso, C. R. (2017). Control of Pratylenchus brachyurus in soybean with Trichoderma spp. and resistance inducers. J. Phytopathol. 165, 1-9. doi: 10.1111/jph.12619

Kramm, K. R., West, D. F., and Rockenbach, P. G. (1982). Termite pathogens: transfer of the entomopathogen Metarhizium anisopliae between Reticulitermes sp. termites. J. Invert. Pathol. 40, 1-6. doi: 10.1016/0022-2011(82)90029-5

Kucera, M., and Malmgren, B. A. (1998). Logratio transformation of compositional data: a resolution of the constant sum constraint. Mar. Micropaleontol. 34, 117-120. doi: 10.1016/S0377-8398(97)00047-9

Laduguie, N., Robert, A., Bonnard, O., Vieau, F., Quere, J. L., Semon, E., et al. (1994). Isolation and identification of (3Z, 6Z, 8E)-3, 6, 8-dodecatrien-1ol in Reticulitermes santonensis Feytaud (Isoptera, Rhinotermitidae): roles in worker trail-following and in alate sex-attraction behavior. J. Insect. Physiol. 40, 781-787. doi: 10.1016/0022-1910(94)90007-8

Lamberty, M., Zachary, D., René, L., Bordereau, R., Robert, A., and Hoffmann, J. A. (2001). Insect immunity: constitutive expression of a cysteine-rich antifungal and a linear antibacterial peptide in a termite insect. J. Biol. Chem. 276, 4085-4092. doi: 10.1074/jbc.M002998200

Little, N. S., Blount, N. A., Londo, A. J., Kitchens, S. C., Schultz, T. P., McConnell, T. E., et al. (2012a). Preference of Formosan subterranean termites for bluestained southern yellow pine sapwood. J. Econ. Entomol. 105, 1640-1644. doi: 10.1603/EC12081

Little, N. S., Riggins, J. J., Schultz, T. P., Londo, A. J., and Ulyshen, M. D. (2012b). Feeding preference of native subterranean termites (Isoptera: Rhinotermitidae: Reticulitermes) for wood containing bark beetle pheromones and blue-stain fungi. J. Insect. Behav. 25, 197-206. doi: 10.1007/s10905-0119293-5
Little, N. S., Schultz, T. P., Diehl, S. V., Nicholas, D. D., Londo, A. J., Musser, F. R., et al. (2013). Field evaluations of subterranean termite preference for sapstain inoculated wood. J. Insect. Behav. 26, 649-659. doi: 10.1007/s10905-013-93 $80-\mathrm{x}$

Liu, L., Li, G. H., Sun, P. D., Lei, C. L., and Huang, Q. Y. (2015). Experimental verification and molecular basis of active immunization against fungal pathogens in termites. Sci. Rep. 5:15106. doi: 10.1038/srep15106

Liu, L., Wang, C. C., Zhao, X. Y., Guan, J. X., and Huang, Q. Y. (2019a). Isocitrate dehydrogenase-mediated metabolic disorders disrupt active immunization against fungal pathogens in eusocial termites. J. Pest. Sci. 93, 291-301. doi: 10.1007/s10340-019-01164-y

Liu, L., Wang, W., Liu, Y. L., Sun, P. D., Lei, C. L., and Huang, Q. Y. (2019b). The influence of allogrooming behavior on individual innate immunity in the subterranean termite Reticulitermes chinensis (Isoptera: Rhinotermitidae). J. Insect. Sci. 19, 1-6. doi: 10.1093/jisesa/iey119

Mankowski, M. E., Schowalter, T. D., Morrell, J. J., and Lyons, B. (1998). Feeding habits and gut fauna of Zootermopsis angusticollis (Isoptera: Termopsidae) in response to wood species and fungal associates. Environ. Entomol. 27, 1315-1322. doi: 10.1093/ee/27.6.1315

Martin, J. S., and Bulmer, M. S. (2018). A lab-based study of temperate forest termite impacts on two common wood-rot fungi. Environ. Entomol. 47, 13881393. doi: $10.1093 / \mathrm{ee} / \mathrm{nvy} 122$

Matsumura, F., Nishimoto, K., Ikeda, T., and Coppel, H. C. (1976). Influence of carbon sources on the production of the termite trail-following substance by Gloeophyllum trabeum. J. Chem. Ecol. 2, 299-305. doi: 10.1007/bf00988279

Mburu, D. M., Ndung'u, M. W., Maniania, N. K., and Hassanali, A. (2011). Comparison of volatile blends and gene sequences of two isolates of Metarhizium anisopliae of different virulence and repellency toward the termite Macrotermes michaelseni. J. Exp. Biol. 214, 956-962. doi: 10.1242/jeb.050419

Mburu, D. M., Ochola, L., Maniania, N. K., Njagi, P. G. N., Gitonga, L. M., Ndung'u, M. W., et al. (2009). Relationship between virulence and repellency of entomopathogenic isolates of Metarhizium anisopliae and Beauveria bassiana to the termite Macrotermes michaelseni. J. Insect. Physiol. 55, 774-780. doi: 10.1016/j.jinsphys.2009.04.015

Myles, T. G. (2002). Alarm, aggregation, and defense by Reticulitermes flavipes in response to a naturally occurring isolate of Metarhizium anisopliae. Sociobiology 40, 243-256. doi: 10.1006/pest.2001.2581

Nishi, O., and Sato, H. (2019). Isolation of Metarhizium spp. from rhizosphere soils of wild plants reflects fungal diversity in soil but not plant specificity. Mycology 10, 22-31. doi: 10.1080/21501203.2018.1524799

Ohmura, W., Tokoro, M., Tsunoda, K., Yoshimura, T., and Takahashi, M. (1995). Termite trail-following substances produced by brown-rot fungi. Mater. Org. 29, 133-146.

Peterson, B. F., and Scharf, M. E. (2016). Lower termite associations with microbes: synergy, protection, and interplay. Front. Microbiol. 7:422. doi: 10.3389/fmicb. 2016.00422

Rath, A. C., Koen, T. B., and Yip, H. Y. (1992). The influence of abiotic factors on the distribution and abundance of Metarhizium anisopliae in Tasmanian pasture soils. Mycol. Res. 96, 378-384. doi: 10.1016/S0953-7562(09)80956-8

Saran, R. K., Millar, J. G., and Rust, M. K. (2007). Role of (3Z, 6Z, 8E)-dodecatrien1-ol in trail following, feeding, and mating behavior of Reticulitermes hesperus. J. Chem. Ecol. 33, 369-389. doi: 10.1007/s10886-006-9229-2

Saravanakumar, K., Dou, K., Lu, Z., Wang, X., Li, Y., and Chen, J. (2018). Enhanced biocontrol activity of cellulase from Trichoderma harzianum against Fusarium graminearum through activation of defense-related genes in maize. Physiol. Mol. Plant. Pathol. 103, 130-136. doi: 10.1016/j.pmpp.2018.05.004

Schrank, A., and Vainstein, M. H. (2010). Metarhizium anisopliae enzymes and toxins. Toxicon 56, 1267-1274. doi: 10.1016/j.toxicon.2010.03.008

Shimizu, S. (2003). Effect of density of the termite, Reticulitermes speratus Kolbe (Isoptera : Rhinotermitidae), on the susceptibilities to Metarhizium anisopliae. Appl. Entomol. Zool. 38, 125-130. doi: 10.1303/aez.2003.125

Staples, J. A., and Milner, R. J. (2000). A laboratory evaluation of the repellency of Metarhizium anisopliae conidia to Coptotermes lacteus (Isoptera: Rhinotermitidae). Sociobiology 36, 133-148.

$\mathrm{Su}, \mathrm{N}$. Y. (2005). Directional change in tunneling of subterranean termites (Isoptera: Rhinotermitidae) in response to decayed wood attractants. J. Econ. Entomol. 98, 471-475. doi: 10.1093/jee/98.2.471 
Sun, J. Z., Fuxa, J. R., Richter, A., and Ring, D. (2014). Interactions of Metarhizium anisoplae and tree-based mulches in repellence and mycoses against Coptotermes formosanus (Isoptera: Rhinotermitidae). Environ. Entomol. 37, 755-763. doi: 10.1093/ee/37.3.755

Waller, D. A., and La Fage, J. P. (1987). Seasonal patterns in foraging groups of Coptotermes formosanus (Rhinotermitidae). Sociobiology 13, 173-181. doi: 10.1002/ps.2780180409

Wang, C., Henderson, G., and Gautam, B. K. (2015). Behavioral response of Formosan subterranean termites (Isoptera: Rhinotermitidae) to soil with high clay content. J. Insect. Behav. 28, 303-311. doi: 10.1007/s10905-015-9505-5

Wang, C., and Powell, J. E. (2004). Cellulose bait improves the effectiveness of Metarhizium anisopliae as a microbial control of termites (Isoptera: Rhinotermitidae). Biol. Control 30, 523-529. doi: 10.1016/j.biocontrol.2004.0 2.007

Weiser, J., and Matha, V. (1986). "Insect pathogens and local microbiota in natural habitats," in Fundamental and Applied Aspects of Invertebrate Pathology, eds R. A. Samson, J. M. Vlak, and D. Peters (Wageningen: International Colloquium), 593-595.

White, T. J., Burns, T., Lee, S., and Taylor, J. (1990). “Amplication and direct sequencing of fungal ribosomal RNA genes for phylogenetics," in PCR Protocols: A Guide to Methods and Applications, eds M. A. Innis, D. H. Gelfand, J. J. Sninsky, and T. J. White (San Diego: Academic Press), 315-322. doi: 10.1016/ b978-0-12-372180-8.50042-1

Wobst, B., Farine, J. P., Ginies, C., Sémon, E., Robert, A., Bonnard, O., et al. (1999). (Z, Z, E)-3, 6, 8-Dodecatrien-1-ol, a major component of trail-following pheromone in two sympatric termite species Reticulitermes lucifugus grassei and R. santonensis. J. Chem. Ecol. 25, 1305-1318. doi: 10.1023/a:1020922708599

Wright, M. S., Raina, A. K., and Lax, A. R. (2005). A strain of the fungus Metarhizium anisopliae for controlling subterranean termites. J. Econ. Entomol. 98, 1451-1458. doi: 10.1093/jee/98.5.1451
Xiong, H. P., Cai, J. C., Chen, X., Liang, S. P., Wen, X. J., and Wang, C. (2019). Effects of Trichoderma fungi on tunneling, aggregation, and colony-initiation preferences of black-winged subterranean termites, Odontotermes formosanus (Blattodea: Termitidae). Forests 10:1020. doi: 10.3390/f10111020

Xiong, H. P., Xue, K. N., Qin, W. Q., Chen, X., Wang, H. F., Shi, X. H., et al. (2018). Does soil treated with conidial formulations of Trichoderma spp. attract or repel subterranean termites? J. Econ. Entomol. 111, 808-816. doi: 10.1093/jee/toy021

Yanagawa, A., and Shimizu, S. (2007). Resistance of the termite, Coptotermes formosanus, Shiraki to Metarhizium anisopliae, due to grooming. Biocontrol 52, 75-85. doi: 10.1007/s10526-006-9020-x

Yanagawa, A., Yokohari, F., and Shimizu, S. (2005). Defense mechanism of the termite, Coptotermes formosanus Shiraki, to entomopathogenic fungi, Japanese. J. Environ. Entomol. Zool. 97, 165-170. doi: 10.1016/j.jip.2007.09.005

Zoberi, M. H. (1995). Metarhizium anisopliae, a fungal pathogen of Reticulitermes flavipes (Isoptera: Rhinotermitidae). Mycologia 87, 354-359. doi: 10.1080/ 00275514.1995.12026539

Zoberi, M. H., and Grace, J. K. (1990). Fungi associated with the subterranean termite Reticulitermes flavipes in Ontario. Mycologia 82, 289-294. doi: 10.1080/ 00275514.1990 .12025883

Conflict of Interest: The authors declare that the research was conducted in the absence of any commercial or financial relationships that could be construed as a potential conflict of interest.

Copyright (c) 2020 Wen, Xiong, Wen, Wen and Wang. This is an open-access article distributed under the terms of the Creative Commons Attribution License (CC BY). The use, distribution or reproduction in other forums is permitted, provided the original author(s) and the copyright owner(s) are credited and that the original publication in this journal is cited, in accordance with accepted academic practice. No use, distribution or reproduction is permitted which does not comply with these terms. 